\title{
COMPARISON OF ROLE OF IVP AND USG IN EVALUATING URETERIC CALCULI DISEASE
}

\author{
Rajesh Rathore1, Rajesh Kumar², Sayal Choudhary3 \\ ${ }^{1}$ Assistant Professor, Department of Radiodiagnosis, R. D. Gardi Medical College. \\ ${ }^{2} 3^{\text {rd }}$ Year Postgraduate Resident, Department of Radiodiagnosis, R. D. Gardi Medical College. \\ ${ }_{33}$ rd Year Postgraduate Resident, Department of Radiodiagnosis, R. D. Gardi Medical College.
}

\begin{abstract}
The incidence of urolithiasis varies according to geographic area, age, and sex distribution. ${ }^{1}$ Various studies have shown that in economically developed countries the prevalence rate ranged between $4 \%$ and $20 \%$. Urolithiasis may affect up to $10 \%$ of the population over the course of a lifetime. In India, upper and lower urinary tract stones occur frequently, but the incidence shows wide regional variation. Smaller stones (Up to $5 \mathrm{~mm}$ ) may cause severe symptoms such as flank pain and nausea, but pass without intervention. Though, they may need supportive care, but larger stones need intervention. Surgery has been used to remove stones (Lithotomy) or to break them all into small pieces (Lithotripsy) since antiquity. Twenty five years ago, open surgery was the sole form of therapy for urolithiasis, but now endourology is the surgical treatment of choice. ${ }^{2}$
\end{abstract}

\section{URETERIC JET}

When the bolus of urine being transmitted through the ureter reaches the terminal portion. It is ejected forcefully into the bladder through the Vesicoureteric Junction (VUJ). This creates a jet of urine that can be seen within the urinary bladder during cystoscopy and grey-scale Ultrasonography (US). Urine secreted from the renal glomeruli is excreted into the upper urinary tract including the collecting system, calyces-pelvis system, and ureter. Although, the precise mechanism of urine drainage through the whole system remains somewhat contentious. The trigger of ureteric jets is undoubtedly the pumping effect of calyceal peristalsis. ${ }^{3}$ The latter comprises an autonomic and rhythmic minor calyceal peristalsis and a pressure-dependent major calyceal peristalsis, and the pressure of the major calyces comes from the resistance of the intrinsic tone of the upper ureter to the urine draining in the renal pelvic volume and tone and the rate of urine inflow. ${ }^{4}$ Continuous discrete boluses of urine drainage into the ureter from pelvis, then fill the ureter, and finally, a ureteric jet is produced after the ureter is wholly filled throughout the autonomic, myogenic, ureteral peristalses. ${ }^{5}$

\section{KEYWORDS}

IVP, USG, Ureteric jet, Resistive Index, Ureterolithiasis

HOW TO CITE THIS ARTICLE: Rathore R, Kumar R, Choudhary S. Comparison of role of IVP and USG in evaluating ureteric calculi disease. J. Evolution Med. Dent. Sci. 2016;5(58):4038-4041, DOI: 10.14260/jemds/2016/923

\section{INTRODUCTION}

The incidence of urolithiasis varies according to geographic area, age, and sex distribution. ${ }^{1}$ Various studies have shown that in economically developed countries, the prevalence rate ranged between $4 \%$ and $20 \%$. Urolithiasis may affect up to $10 \%$ of the population over the course of a lifetime. In India, upper and lower urinary tract stones occur frequently, but the incidence shows wide regional variation. Smaller stones (Up to $5 \mathrm{~mm}$ ) may cause severe symptoms such as flank pain and nausea, but pass without intervention. Though, they may need supportive care, but larger stones need intervention. Surgery has been used to remove stones (Lithotomy) or to break them all into small pieces (Lithotripsy) since antiquity. Twenty five years ago, open surgery was the sole form of therapy for urolithiasis, but now endourology is the surgical treatment of choice. $^{2}$

\section{Ureteric Jet}

When the bolus of urine being transmitted through the ureter reaches the terminal portion, it is ejected forcefully into the

Financial or Other, Competing Interest: None.

Submission 18-05-2016, Peer Review 08-07-2016,

Acceptance 14-07-2016, Published 21-07-2016.

Corresponding Author:

Dr. Rajesh Kumar,

Room No. 120,

RMO Hostel,

R. D. Gardi Medical College.

E-mail: tokasrajesh@gmail.com

DOI: $10.14260 /$ jemds $/ 2016 / 923$ bladder through the Vesicoureteric Junction (VUJ). This creates a jet of urine that can be seen within the urinary bladder during cystoscopy and grey-scale Ultrasonography (US). Urine secreted from the renal glomeruli is excreted into the upper urinary tract including the collecting system, calyces-pelvis system, and ureter. Although, the precise mechanism of urine drainage through the whole system remains somewhat contentious. The trigger of ureteric jets is undoubtedly the pumping effect of calyceal peristalsis. ${ }^{3}$ The latter comprises an autonomic and rhythmic minor calyceal peristalsis and a pressure-dependent major calyceal peristalsis, and the pressure of the major calyces comes from the resistance of the intrinsic tone of the upper ureter to the urine draining in, the renal pelvic volume and tone, and the rate of urine inflow. ${ }^{4}$ Continuous discrete boluses of urine drainage into the ureter from pelvis, then fill the ureter, and finally, a ureteric jet is produced after the ureter is wholly filled, throughout the autonomic, myogenic, ureteral peristalses. ${ }^{5}$

\section{Statement of Study}

This study will compare the two modalities for the assessment of ureteric obstruction in ureteric calculus disease in the patients that need intervention.

\section{MATERIALS AND METHODS}

In this study, all 30 obstructed ureters in 54 patients were studied. There were 25 males and 5 females in the study.

The patients had signs and symptoms referable to urinary 
tract obstruction such as pain, haematuria, lump, acute retention, dysuria, and cystitis. They were clinically evaluated and on suspicion of obstruction they were subjected to radiological evaluation in the form of intravenous pyelography, conventional USG, and then duplex Doppler USG (Renal resistive index and ureteric jet). All patients were prepared prior to IVU by administering laxatives and deflating agents. Care was taken that creatinine levels were within normal limits before IVU was performed. Post-contrast films were taken immediately and then at 5-, 15-, and 30-minute intervals. In patients with poor renal function where no opacification of the urinary tract was seen, films were taken at 45 and 60 minutes and even later if required.

A standing column of dye in the ureterogram phase was considered as a sign of obstruction and these patients were then subjected to renal ultrasound using a $3.5 \mathrm{MHz}$ transducer (With linear and sector transducer). Sonography was done in supine and prone positions. All the ureters with obstruction and hydronephrosis detected on IVU and subsequently by conventional sonography were subjected to duplex Doppler sonography to determine the increase in resistance to blood flow in renal arteries [At the level of hilum] and hence increase in resistive index and ureteric jets. ${ }^{6}$ Physiologically, urine flowing from the ducts of Bellini passes under active peristalsis from the minor calyces into the major calyces and hence the renal pelvis that contracts at a rate dependent on diuresis transport of urine into the upper ureter. Therefore, before ultrasonographic observation of the intravesical ureteric jets of urine, adequate hydration of the kidneys is necessary. ${ }^{7}$ The subjects were asked to take about 1,000-1,500 $\mathrm{mL}$ of water and a cup of coffee and wait for half an hour. Ultrasonographic observation of the ureteric jets is initiated at about 30 minutes after the first dose of water or coffee drunk or whenever the subject feels distension of urinary bladder and the need to void, but were asked to hold up till the jet was visualised on the Doppler.

\section{GRADING}

Grade 0: No dilation with calyceal walls apposed.

Grade 1: (Mild)-dilation of the renal pelvis without dilation of the calyces nor parenchymal atrophy.

Grade 2: (Mild)-dilation of the renal pelvis and calyces without parenchymal atrophy.

Grade 3: (Moderate)-moderate dilation of the renal pelvis and calyces with blunting of the fornicies and flattening of papillae. Grade 4: (Severe)-gross dilation/ballooning of the renal pelvis and calyces with loss of borders between the renal pelvis and calyces and renal atrophy seen as cortical thinning.

The grading was based upon the principle that any chronic obstruction to the outflow of urine will eventually lead to backpressure changes in the kidneys thereby distorting the normal renal anatomy to various extents depending upon the chronicity and degree of obstruction whether complete or partial. ${ }^{8}$

Previous studies on renal resistive index ${ }^{9}$ demonstrated the normal value to be less than 0.7 . A value greater than this is highly suggestive of obstruction.

\section{CALCULATING THE RENAL RESISTIVE INDEX}

Renal Resistive Index is defined as the Ratio of the difference of

[Peak systolic (a) and peak diastolic velocity (b)] to peak systolic velocity (a-b/a) in a defined vessel. ${ }^{10}$

Most examinations were performed with $3.5 \mathrm{MHz}$ transducer. The Doppler sample volume is set to $2 \mathrm{~mL}$ at $5 \mathrm{~mm}$ and placed at corticomedullary junction of the kidney (Arcuate arteries) or along the border of medullary pyramids (Interlobar arteries).

An RI of $>0.70$ was considered as suggestive of obstruction.

\section{Measurement of Ureteric Jets}

The probe (3.5 MHz) of a Colour Doppler scanner was placed over the suprapubic region to face the base of the bladder and orientate the slice of ureteric jets of both sides. Doppler waveforms of the ureteric jets are continuously recorded during the steady diuresis phase of urine ejaculation for each side with sonoprinter papers and videotapes. Usually, 5 to 10 continuous Doppler waveforms were selected for spectral analysis. The measurements of Doppler waveforms spectral analysis included the average jet velocity ( $\mathrm{V}_{\text {mean }}$, centimetre/second).

In the study, we compared the ureteric jet velocities on obstructed and non-obstructed sides to quantify obstruction. ${ }^{11}$ It has been observed in previous studies that on nonobstructed sides, the values of these jets varied from 20-60 $\mathrm{cm} / \mathrm{s}$ and less than these values on the obstructed sides. These values were used as the reference standards in our study. The values of ureteric jets on the obstructed site were classified in three groups: $10-7 \mathrm{~cm} / \mathrm{s}, 7-4 \mathrm{~cm} / \mathrm{s}$, and $<3$ or equal to $3 \mathrm{~cm} / \mathrm{s}$ and were graded as mild, moderate, and severe obstruction respectively.

\section{DISCUSSION}

Renal Doppler US is a highly sensitive and specific test that can be useful in the diagnosis of acute unilateral renal obstruction. Doppler US can be used to measure renal blood flow as well as to calculate RI. The RI is a ratio of peak systolic velocity and end-diastolic velocity derived from the Doppler spectrum. It is a physiological parameter that ensures indirect measurement of the degree of resistance within intrarenal vessels. Previous studies have determined that the threshold RI (Measured at the arcuate or interlobular arteries) to identify obstructive uropathy is 0.70. Above this value, the dilation can be considered to be of obstructive origin with a $93 \%$ sensitivity and $100 \%$ specificity. Doppler US with measurement of the RI in the intrarenal arteries is very useful as obstruction leads to intrarenal vasoconstriction with a consecutive increase of the $\mathrm{RI}$ above the upper limit of 0.7 ; however, the case is different for non-obstructive dilatation. Radiologists differentiate physiological hydronephrosis from urinary tract obstruction using the RI. US is an alternative method to IVU as it does not involve ionising radiation or intravenous contrast; however, it is less accurate than IVU for both diagnosis of obstruction and lithiasis. Although, noncontrast helical CT has become the gold standard for the diagnosis of ureterolithiasis. It is not used widely due to its inaccessibility and the radiation exposure involved. Doppler US is noninvasive, painless, readily available, and relatively easy to apply and it entails no radiation exposure. It would be especially useful in patients in whom intravenous contrast agent administration must be avoided (Pregnancy, contrast agent allergy, and renal dysfunction). According to the results of our study, RI is useful for the early identification of renal colic patients in the emergency department, particularly for those who must avoid 
radiation and contrast agents.

\section{OBSERVATION AND RESULTS}

\begin{tabular}{|c|c|c|}
\hline & Number & Percentage \\
\hline$<=20$ Years & 2 & 6.7 \\
\hline $21-40$ Years & 22 & 73.3 \\
\hline 41-60 Years & 2 & 6.7 \\
\hline$>60$ Years & 4 & 13.3 \\
\hline Total & $\mathbf{3 0}$ & $\mathbf{1 0 0 . 0}$ \\
\hline
\end{tabular}

Table 1: Distribution of Patients According to Age $(\mathrm{N}=30)$

Age group of 21-40 years is most commonly affected.

\begin{tabular}{|c|c|c|}
\hline Gender & Number & Percentage \\
\hline Female & 5 & 16.7 \\
\hline Male & 25 & 83.3 \\
\hline Total & $\mathbf{3 0}$ & $\mathbf{1 0 0 . 0}$ \\
\hline \multicolumn{3}{|c|}{$\begin{array}{c}\text { Table 2: Distribution of Patients } \\
\text { According to Gender }(\mathbf{N}=\mathbf{3 0})\end{array}$} \\
\hline
\end{tabular}

Males are more affected in comparison with females.

\begin{tabular}{|c|c|c|}
\hline Religion & Number & Percentage \\
\hline Hindu & 25 & 83.3 \\
\hline Jain & 2 & 6.7 \\
\hline Muslim & 3 & 10.0 \\
\hline Total & $\mathbf{3 0}$ & $\mathbf{1 0 0 . 0}$ \\
\hline \multicolumn{3}{|c|}{ Table 3: Distribution of Patients } \\
According to Religion (N=30)
\end{tabular}

In present study, Hindu population is more affected rather other religion.

\begin{tabular}{|c|c|c|}
\hline & Number & Percentage \\
\hline Upper Middle Class & 1 & 3.3 \\
\hline Middle Class & 6 & 20.0 \\
\hline Lower Middle Class & 2 & 6.6 \\
\hline Lower Class & 21 & 70.0 \\
\hline Total & 30 & 100.00 \\
\hline \multicolumn{3}{|c|}{$\begin{array}{c}\text { Table 4: Distribution of Patients According } \\
\text { to Socioeconomic Status }(N=30)\end{array}$} \\
\hline
\end{tabular}

In present study, lower class population is more affected rather other category. $(\mathrm{N}=30)$.

\begin{tabular}{|c|c|c|}
\hline Location of Stone & Number & Percentage \\
\hline Upper Third & 7 & 23.3 \\
\hline Middle Third & 10 & 33.3 \\
\hline Lower Third & 13 & 43.3 \\
\hline Total & 30 & 100.0 \\
\hline \multicolumn{3}{|c|}{$\begin{array}{l}\text { Table 5: Distribution of Patients } \\
\text { According to Location of Stone }(N=30)\end{array}$} \\
\hline
\end{tabular}

In present study, lower third population is most common location. $(\mathrm{N}=30)$.

\begin{tabular}{|c|c|c|}
\hline Symptoms & Number & Percentage \\
\hline Flank Pain & 30 & 100.0 \\
\hline Burning in Micturition & 3 & 10.0 \\
\hline Haematuria & 2 & 6.7 \\
\hline
\end{tabular}

In present study, flank pain is present in every patient. $(\mathrm{N}=30)$.

\begin{tabular}{|c|c|c|}
\hline Duration of Symptoms & Number & Percentage \\
\hline <2 Months & 9 & 30.0 \\
\hline 2-6 Months & 19 & 63.3 \\
\hline 7-12 Months & 2 & 6.7 \\
\hline >12 Months & 0 & 0.0 \\
\hline Total & $\mathbf{3 0}$ & $\mathbf{1 0 0 . 0}$ \\
\hline $\begin{array}{r}\text { Table 7: Distribution of Patients According } \\
\text { to Duration of Symptoms }\end{array}$ \\
\hline
\end{tabular}

In present study, duration of symptoms between 2-6 months is more common.

\begin{tabular}{|c|c|c|}
\hline Location of Stone & Number & Percentage \\
\hline Upper One-Third & 7 & 23.33 \\
\hline Middle One-Third & 9 & 30.00 \\
\hline Upper and Middle One-Third & 1 & 3.34 \\
\hline Lower One-Third & 13 & 43.33 \\
\hline Total & 30 & 100.0 \\
\hline \multicolumn{3}{|c|}{$\begin{array}{c}\text { Table 8: Distribution of Patients According } \\
\text { to Location of Stone }(N=30)\end{array}$} \\
\hline
\end{tabular}

In present study, lower one-third location of stone is more common.

\begin{tabular}{|c|c|c|}
\hline IVU Grading & Number & Percentage \\
\hline Mild obstruction (0-2) & 23 & 76.67 \\
\hline Moderate obstruction (3) & 5 & 16.67 \\
\hline $\begin{array}{c}\text { Severe or gross } \\
\text { obstruction (4-5) }\end{array}$ & 2 & 6.66 \\
\hline Total & $\mathbf{3 0}$ & $\mathbf{1 0 0 . 0 0}$ \\
\hline \multicolumn{2}{|c|}{ Table 9: Distribution of Patients } \\
According to IVU Grading (N=30) \\
\hline
\end{tabular}

\begin{tabular}{|c|c|c|c|c|}
\hline Grading & $\begin{array}{c}\text { Number } \\
\mathbf{1}\end{array}$ & $\begin{array}{c}\text { Number } \\
\mathbf{2}\end{array}$ & $\begin{array}{c}\mathbf{Z} \\
\text { Value }\end{array}$ & $\begin{array}{c}\mathbf{P} \\
\text { value }\end{array}$ \\
\hline Mild Obstruction & 23 & 4 & 6.39 & 0.000 \\
\hline Moderate Obstruction & 5 & 13 & 2.36 & 0.018 \\
\hline $\begin{array}{c}\text { Severe or Gross } \\
\text { Obstruction }\end{array}$ & 2 & 13 & 3.62 & 0.000 \\
\hline Total & $\mathbf{3 0}$ & $\mathbf{3 0}$ & & \\
\hline
\end{tabular}

Number 1-Sample 1

Number 2-Sample 2

\begin{tabular}{|c|c|c|c|c|}
\hline $\begin{array}{c}\text { Ureteric Jet } \\
\text { Side }\end{array}$ & $\mathbf{N}$ & Mean \pm SD & $\begin{array}{c}\text { 't' } \\
\text { Value }\end{array}$ & $\begin{array}{c}\mathbf{P} \\
\text { value }\end{array}$ \\
\hline Obstructed Side & 28 & $4.30 \pm 2.61$ & 11.05, & $0.000^{*}$ \\
\cline { 1 - 2 } $\begin{array}{c}\text { Non-Obstructed } \\
\text { Side }\end{array}$ & 29 & $23.29 \pm 8.97$ & \\
\cline { 1 - 1 } Table 10: Comparison of Mean Ureteric Jets $(\mathbf{N}=\mathbf{3 0})$ \\
\hline
\end{tabular}

Unpaired ' $\mathrm{t}$ ' test was applied. $\mathrm{P}<0.05$, significant.

\section{CONCLUSION}

Real-time ultrasound is nowadays worldwide available in the morphological detection of reno-ureteral abnormality simply because of its reliability, no invasion, and convenience. Colour Doppler US on the basis of real-time ultrasound can be used to evaluate renal vascularity and haemodynamics, which adds more ultrasonographic information in diagnosis of renoureteral diseases. In addition, on observation of the intravesical ureteric jet and through the measurements and analysis of the ureteric jet DW under well renal hydration, we can understand more about the ureterodynamics.

By measurement of ureteric jet frequency, average jet 
velocity, and jet duration from the ureteric jet DW, obstructive uropathy can be detected. With calculation of the ureteric jet, unilateral renal function can also be assessed. For diagnosis of reno-ureteral abnormality, combined real-time and colour Doppler ultrasonography could therefore be much of value and play a certain important role clinically.

Doppler sonography currently has little in the evaluation of renal disorders. The Doppler arterial waveform is the product of the interaction of a number of factors (Hydration status of the patient, use of diuretics, age of the patient, pregnancy, etc.) sometimes in a complicated way. Once these factors are better understood and if they can be taken into account correctly understood Doppler sonography may be a useful clinical tool to evaluate renal dysfunction and study obstructive uropathies. A more sophisticated functional approach may allow radiologists to maintain a pre-eminent role in the imaging assessment of renal disease.

In special circumstances like pregnancy, prerenal failure, renal failure, and where intravenous urography cannot be used or should be avoided colour Doppler waveform studies (Ureteric Jet) and renal resistive index may prove to be valuable.

\section{SUMMARY}

- Type of study: Cross Sectional.

- This study was done to find out whether Duplex Doppler can replace IVP for diagnosing obstructive uropathy; namely ureteric calculus disease.

- $\quad$ Total of 30/54 patients were studied (The ones found to have symptoms of ureteric calculus).

- About $83 \%$ of the patients were males and $17 \%$ were females.

\section{Colour Doppler has several Advantages}

1. It can detect early obstruction and renal impairment.

2. It can be used to study obstructive uropathy in a pregnancy where IVP/IVU is contraindicated.

3. IVP is avoided in children whereas DDUSG can be used to study obstructive uropathy in children.

4. DDUSG can be used in prerenal failure/renal failure and in condition of disturbed/impaired renal function. IVU is a contraindication here. There is no risk of contrast nephropathy with DDUSG

5. DDUSG is cheap and quick as compared to IVP.

\section{REFERENCES}

1. Onur MR, Cubuk M, Andic C, et al. Role of resistive index in renal colic. Urol Res 2007;35(6):307-12.

2. Pepe P, Motta L, Pennisi M, et al. Functional evaluation of the urinary tract by colour-Doppler ultrasonography (CDU) in 100 patients with renal colic. Eur J Radiol 2005;53(1):131-5.

3. Geavlete P, Georgescu D, Cauni V, et al. Value of duplex Doppler ultrasonography in renal colic. Eur Urol 2002;41(1):71-8.

4. Safarinejad MR. Adult urolithiasis in a population-based study in Iran: prevalence, incidence, and associated risk factors. Urol Res 2007;35(2):73-82.

5. Haroun A. Duplex Doppler sonography in patients with acute renal colic: prospective study and literature review. Int Urol Nephrol 2003;35(2):135-40.

6. Gurel S, Akata D, Gurel K, et al. Correlation between the renal Resistive Index (RI) and nonenhanced computed tomography in acute renal colic: how reliable is the RI in distinguishing obstruction? J Ultrasound Med 2006;25(9):1113-20.

7. Chan VO, Buckley O, Persaud T, et al. Urolithiasis: how accurate are plain radiographs? Can Assoc Radiol J 2008;59(3):131-4.

8. Amin MU, Ghaffar A. Intrarenal and intravesical colour Doppler sonography in patients with acute renal colic. J Surg Pak 2004;9(3):40-2.

9. Tublin ME, Bude RO, Platt JF. The resistive index in renal Doppler sonography: where do we stand? AJR 2003;180(4):885-92.

10. Bateman GA, Cuganesan R. Renal vein Doppler sonography of obstructive uropathy. AJR 2002;178(4):921-5.

11. Kmetec A, Peskar-Babnik D, Buturovic-Ponikvar J. Timedependent changes of resistive index in acute renal obstruction during nonsteroidal drug administration. BJU Int 2002;89(9):847-50. 